\title{
Influence of Post-treatment Methods on Pressure Change of Filter Bag
}

\author{
Yin Yihua ${ }^{1, \mathrm{a}}$, Yu Bin ${ }^{2, \mathrm{~b}}$ and Han $\operatorname{Jian}^{2, \mathrm{c}}$ \\ ${ }^{1}$ School of Materials and Textiles, Zhejiang Sci-Tech University, Hangzhou, Zhejiang 310018, China; \\ ${ }^{2}$ Zhejiang Prov. Key Lab. of Industrial Textile Materials, Hangzhou, Zhejiang 310018, China; \\ âinyihua1990@126.com, bhanjian8@zstu.edu.cn, cyubin7712@163.com
}

\begin{abstract}
The PPS needle-punched non-woven filters with different post-treatments were studied by filter testing system. The pressure drop was measured at various filtration velocity, dust deposition time and the temperature during the experiment; and the effect of dust-cleaning as the consequence of pressure of filter bag was measured. The results showed that post-treatments transformed the surfaces of filters, and the dust formation differed greatly. Excessively high filtration velocity decreased the peak pressure in the process of dust-cleaning. The pressure of filter bag was increased as the dust layers were thickened. The higher temperature in filtration rose the peak pressure of filter bag, but decreased the rate of rising.
\end{abstract}

Keywords: bag filter; dust-cleaning performance; peak pressure of filter bag; rising rate of peak pressure

\section{Introduction}

Bag filter has the efficient collection efficiency and stable performance which is widely used in the field of industrial dedusting. Dust cleaning efficiency is key to improve the efficiency of dust-catcher [1-2]. The cleaning effect is directly related to the resistance of filter, energy consumption, working life of filter bag, etc. Humphries and Madden [3] found that when the filter was in the balanced filtration state, the main affecting factors of dust-cleaning were the peak pressure and its arrival time. Further, high pressure and short arrival time indicated better dust-cleaning effect. Wang Haitao [4] studied the theory of blowing mechanism, then put forward an argument that arrival peak velocity was related to the dust-cleaning effect. Liu and Mao [5] simulated the mechanical mechanism of dust-cleaning process, and came to a conclusion that maximum opposite acceleration was closely related to dust removing force. Currently the peak pressure of filter bag, peak pressure rising rate and maximum opposite acceleration were the three main indicators to evaluate the cleaning effect [6-7]. Now many papers discussed the dust-cleaning on how to perfect the equipment parameters, however, few papers studied the filter properties on the dust-cleaning effect. This paper studied the effect of filters with different post-treatments on dust-cleaning process. 


\section{Experiment Procedure}

Experimental material: choosing four post-treatment PPS needle non-woven filters (specifications: $\Phi 130 \mathrm{~mm} \times 1000 \mathrm{~mm})$; dust category: talcum powder $(18 \mu \mathrm{m}$, Shanghai Liangjiang Titanium Dioxide Chemical Co., Ltd.). Table 1 shows the basic performances of four kinds of filters.

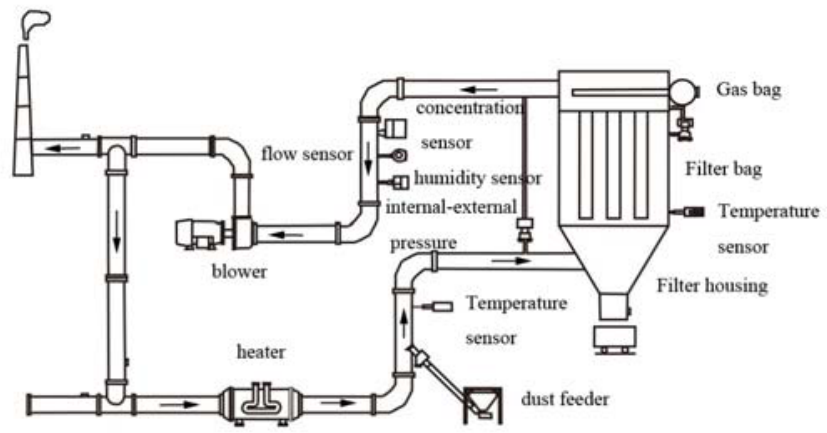

Fig.1 The sketch of the filter system

Table.1 The Basic Performances Of Filters With Different Post-Treatments

\begin{tabular}{ccccc}
\hline Filter & $\begin{array}{c}\text { Thickness/ } \\
(\mathrm{mm})\end{array}$ & $\begin{array}{c}\text { Grammage } / \\
\left(\mathrm{g} \cdot \mathrm{m}^{-2}\right)\end{array}$ & $\begin{array}{c}\text { Air permeability/ } \\
\left(\mathrm{L} \cdot \mathrm{m}^{-2} \cdot \mathrm{s}^{-1}\right)\end{array}$ & Mean pore size/ $(\mu \mathrm{m})$ \\
\hline Untreated filter & 3.23 & 578.0 & 300.4 & 12.7 \\
$\begin{array}{c}\text { Singeing filter } \\
\text { PTFE emulsion }\end{array}$ & 1.76 & 568.8 & 154.7 & 7.8 \\
$\begin{array}{c}\text { impregnated filter } \\
\text { PTFE }\end{array}$ & 1.78 & 586.7 & 164.3 & 8.4 \\
$\begin{array}{c}\text { microporous } \\
\text { membrane filter }\end{array}$ & 2.10 & 584.8 & 82.2 & 4.4 \\
\hline
\end{tabular}

Experimental apparatus: filter testing system (Zhejiang Jiehua Co.,Ltd), the system has a set of bag filter simulator to detect the working performance of filter. The system consists of blower, dust feeder, heater and filter housing. Filtration velocity, dust amount and temperature are controllable. Fig. 1 is the sketch of the filter system, It is under inlet bag-type and external-bay dust collector. The filter housing is the key in the system in which there are six filter bags. The system run by blower to circulate the air. Filtration velocity is controlled by blower's frequency, the range is from $5 \mathrm{~Hz}$ to $50 \mathrm{~Hz}$. Dust concentration transducer, flow transducer and inlet-outlet pressure transducer are installed in the system. Pressure transducer and acceleration transducer are equipped in the bottom of the filter bag. Pressure and acceleration change can be recorded in the dust-cleaning process. 


\section{Results and Discussion}

The peak pressure of filter bag, pressure rising rate and maximum opposite acceleration are detected in this experiment. These three factors will be discussed in the paper whether they have relationship with the effect of dust-cleaning. The peak pressure of the filter bag is the maximum static pressure difference in the dust-cleaning process. High peak pressure means larger deformation of filter bag, and the dust was easy to be blown away. Pressure rising rate is the ratio of peak pressure and arrival time. High pressure rising rate means rapid expansion. It makes for resisting the adhesion force among dust, or between dust and filter. Maximum opposite acceleration is the maximum acceleration when filter interface shrinks reversely. Fig. 2 shows the change of peak pressure of blower frequency at $10 \mathrm{~Hz}$, $15 \mathrm{~Hz}$ and $20 \mathrm{~Hz}$. The results indicate that the peak pressure is decreasing when the blower frequency goes up. For the direction of filtration is from outside to inside, it's opposite to the direction of pulse jet. So higher filtration velocity will weaken the pressure at the bottom of filter bag and affect the dust-cleaning effect. The peak pressure of the post-process filters is greater than untreated filter.

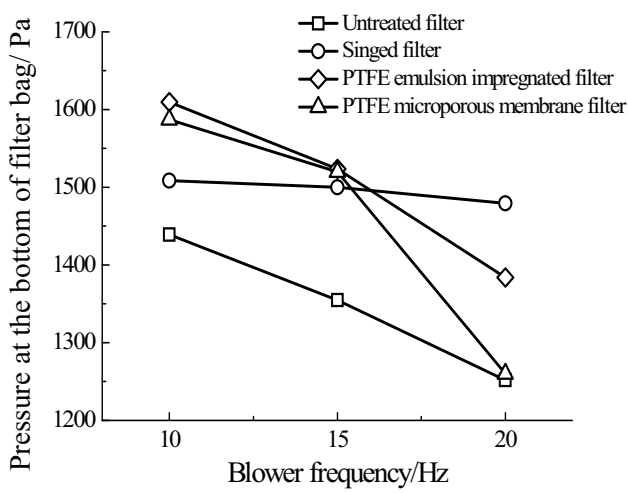

Fig.2 Change of peak pressure at variant blower frequency

Fig.3-6 shows pressure change of the different post-treatment filters. The two curves represent the filtration time before and after two hours. The results indicate that the pressure increases after two hours' filtration. Compared with the four filters, the pressure rising range of untreated filter and impregnated filter are larger. The dust in those filters is more than others. The singeing filter and membrane filter have smooth surface, The dust is hard to enter, and easy to be cleaned from the surface.

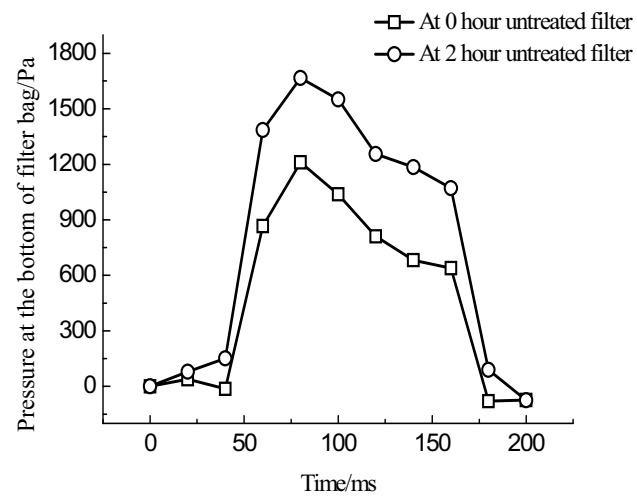

Fig.3 Pressure change of the untreated filter 


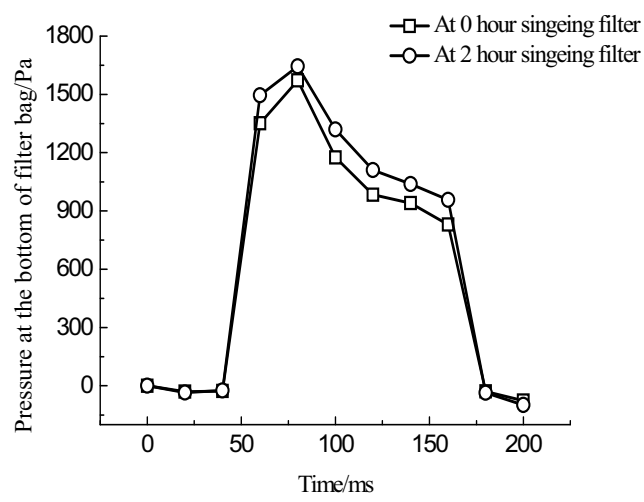

Fig. 4 Pressure change of the singeing filter

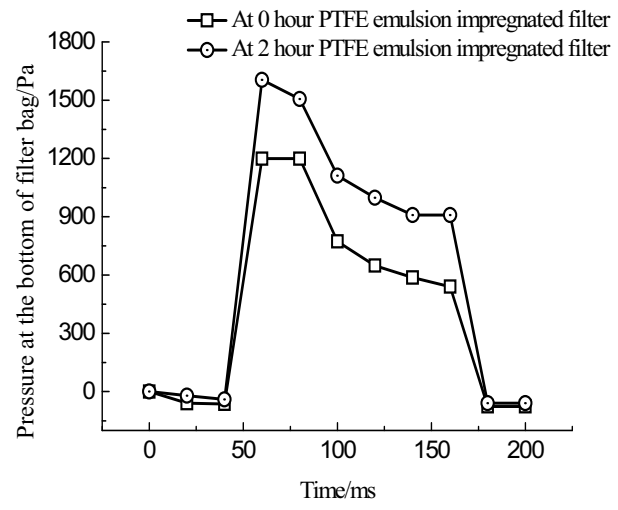

Fig.5 Pressure change of the impregnated filter

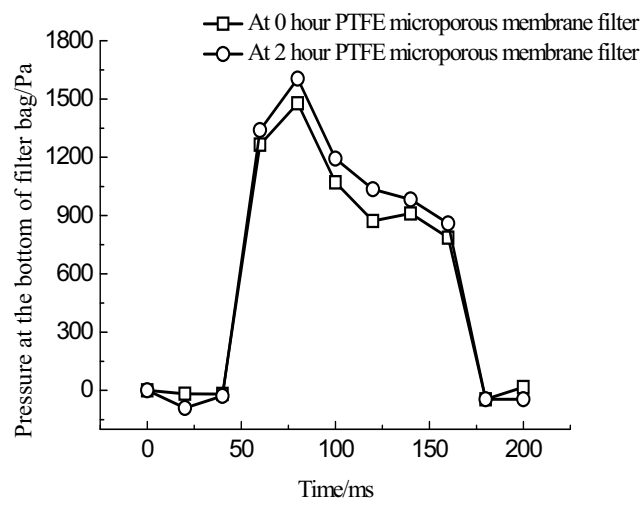

Fig.6 Pressure change of the membrane filter

The temperature has the great influence on bag filter. First the humidity in bag filter is controlled by temperature. Fig.7 shows the humidity change when the temperature changes. When temperature rises, water vapor in bag filter decreases. Thus, the dust in filter will be dry. The humidity of dust affects the adhesion force among dust, between dust and filter. Fig. 8 shows the pressure change of membrane filter when the temperature rises. The results show that the peak pressure is rising greatly when the temperature from $16^{\circ} \mathrm{C}$ to $60^{\circ} \mathrm{C}$. But 
the curves in the first $60 \mathrm{~ms}$ are similar. In the rest time, the curve at $60^{\circ} \mathrm{C}$ goes down rapidly after reaching the peak. The curve at $60^{\circ} \mathrm{C}$ keeps rising and decreasing slowly. The high temperature makes the pressure of the bag filter rise. The comparison of the peak pressure and peak pressure rising rate of four filters have been summarized in the Table. 2 . They have opposite trend. The curve at $60^{\circ} \mathrm{C}$ has higher peak pressure and lower peak pressure rising rate. But the lower peak pressure rising rate shows that the effect of dust-cleaning can not be improved.

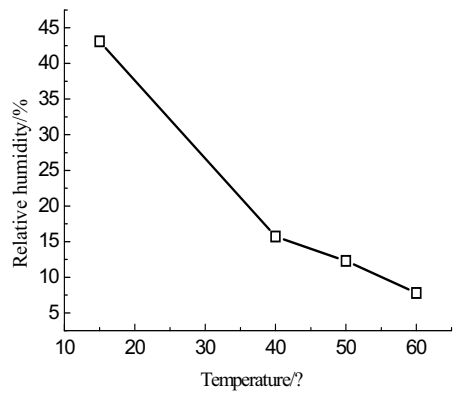

Fig.7 Change of humidity in different temperature

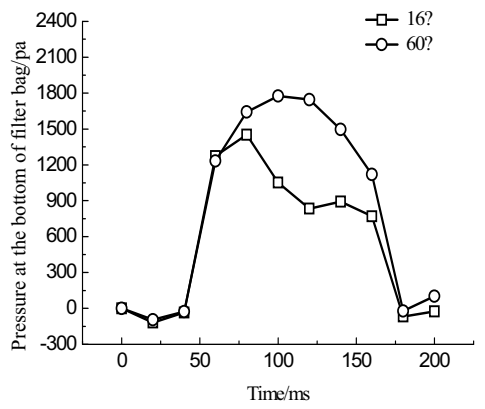

Fig.8 Change of pressure in different temperature

Table.2 The Peak Pressure And Rising Rate Of Four Filters

\begin{tabular}{ccccc}
\hline \multirow{2}{*}{ Filter form } & \multicolumn{3}{c}{$16{ }^{\circ} \mathrm{C}$} & \multicolumn{2}{c}{$60^{\circ} \mathrm{C}$} \\
\cline { 2 - 5 } & $\begin{array}{c}\text { Peak } \\
\text { pressure } \\
/ \mathrm{Pa}\end{array}$ & $\begin{array}{c}\text { peak pressure } \\
\text { rising rate } \\
/\left(\mathrm{Pa}^{\circ} \mathrm{ms}^{-1}\right)\end{array}$ & $\begin{array}{c}\text { Peak } \\
\text { pressure } \\
/ \mathrm{Pa}\end{array}$ & $\begin{array}{c}\text { peak pressure } \\
\text { rising rate } \\
/\left(\mathrm{Pa} \cdot \mathrm{ms}^{-1}\right)\end{array}$ \\
\hline Untreated filter & 1622.8 & 20.3 & 1970.6 & 12.3 \\
\hline Singeing filter & 1407.3 & 17.6 & 1663.1 & 13.9 \\
\hline $\begin{array}{c}\text { PTFE emulsion } \\
\text { impregnated filter }\end{array}$ & 1656.6 & 27.6 & 1991.3 & 14.2 \\
\hline $\begin{array}{c}\text { PTFE micro-porous } \\
\text { membrane filter }\end{array}$ & 1452.1 & 18.2 & 1775.6 & 17.7 \\
\hline
\end{tabular}


Figure.9 indicated the surfaces of filters with different post-treatments before filtration. Clear fibers were found in untreated filter. Larger area of coke-like substance was covered at the surface of singeing filter. The impregnated filter was dipping with PTFE emulsion solid substance. The membrane filter was coated with micro-porous membrane, so fibers can not be seen clearly. Predictably, filters with post-treatments have smaller aperture and worse air permeability, but more glazed surfaces. Fig.10 shows the surfaces of filters with different post-treatments after filtration. Different surfaces of filters have different dust layer features. The dust layer of membrane filter was compact, limited fibers can be revealable, So the dust was stopped out of filter. The dust adhered on singeing filter and impregnated filter tightly, little dust came into the filters. But many fibers were appeared from the dust layer as the filter was untreated. So the holes of untreated filter had most dust.

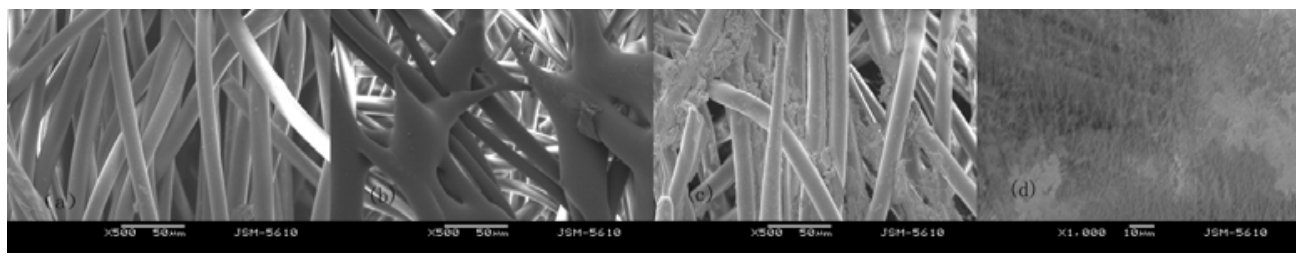

(a.untreated filter; b.singeing filter; c.PTFE emulsion impregnated filter; d.PTFE micro-porous membrane filter)

Fig.9 SEM images of four post-treatments filters before filtration

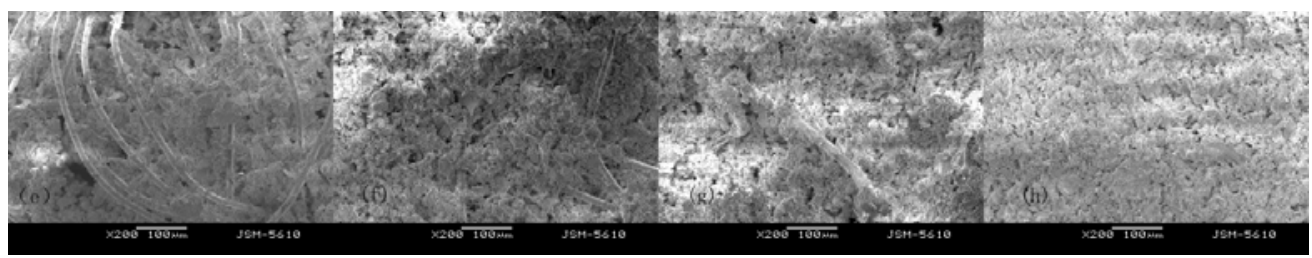

(e.untreated filter; f.singeing filter; g.PTFE emulsion impregnated filter; h.PTFE micro-porous membrane filter)

Fig.10 SEM images of four post-treatments filters after filtration

\section{Summary}

From the study, it may be summed up that high filtration velocity will weaken the pressure of filter bag. The peak pressure of the post-treatment filters were greater than untreated filter. Lowering filtration velocity was a method to reduce the pressure of bag filter. The pressure of filter bag rose by increasing the thickness of dust layer. The singeing filter and membrane filter had smaller pressure rise because of the smooth surface; the change of temperature influenced the humidity of bag filter, the rising rate of peak pressure indicated temperature had little effect on dust-cleaning; the post-treating methods of the filters had significant effect on the dust formation and degree of dust-cleaning.

\section{Acknowledgment}

This work was financially supported by Special Research Found for the Doctoral Program of Higher Education (20133318110001). 


\section{References}

1. XIAO Rongxu.Bag-House Dust Filter and High Temperature Resistance Filtration Materials in China[J].Technical Textiles,2005,3:4-6.

2. Du Liuliu, Shen Henggen.Research Progress on the Dust Cleaning of Bag Filter[J].Building Energy \& Environment,2007,26(5):25-29.

3. Humphries.W,Madden J.J.Fabric Filtration for Coal-fired Boilers;Dust Dislodgement in Pulse Jet Filter[J].Filtration \& Separation,1983,2(21):40-44.

4. Wang Haitao,Zhang Dianyin.Research on Dust Cleaning Mechanism of Pulse-jet Filter Bag[J]. Environmental Protection in Metallurgical Industry,2010,4:22-25.

5. LIU Hua,MAO Qingxi,HUANG Jihong,Analysis of Cleaning Efficiency of Microporous Membrane Filter[J].Building Energy \& Environment,2002,3.9-12.

6. Kanaoka C,Kishima T,Furuuchi M.Cleaning Mechanism of Dust from Ceramic Filter Element[A].In: Proceedings of the 4th Gas Cleaning at High Temperature[C].Karlsrube:Braun Pritconsult GmbH,1991.142-152.

7. Sievert J,Loffler F.Dust Cake Release from Non-woven Fabrics[J].Filtration and Separation, 1987,24(6):424-427. 